www.nature.com/pj

\title{
Thermal solid-state polymerization of a divalent metal salt of an unsaturated carboxylic acid and the effects of additives
}

\author{
Junki Tsuchida $^{1}$, Yosuke Saito ${ }^{1}$, Saki Sato ${ }^{1}$, Ushio Yuki ${ }^{1}$, Satoshi Inayama ${ }^{1}$, Yoko Tatewaki ${ }^{1}$, Shuji Okada ${ }^{1}$, \\ Ayaka Shindo $^{2}$, Chiemi Mikura ${ }^{2}$, Kazuhisa Fushihara ${ }^{2}$ and Mikio Yamada ${ }^{2}$
}

Thermal solid-state polymerization of zinc diacrylate (ZDA) alone and with additives, such as diphenyl disulfide (DPDS) and thiophenol (TP) derivatives and dicumyl peroxide (DCP), was investigated. The solid-state polymerization of ZDA was confirmed to be non-topochemical, and the main polymer structure was found to be polyacrylate with acrylate or polyacrylate connected by $\mathrm{Zn}^{2+}$ although a part of the monomer structure was eliminated during the polymerization. The polymerization rates were estimated by conversion from ZDA to its polymer, which was determined gravimetrically. The qualitative order of the polymerization rate was ZDA $<$ ZDA-DPDS, ZDA-TP $<<$ ZDA-DPDS-DCP, ZDA-TP-DCP $<$ ZDA-DCP, in which each additive was mixed with a 1/60 molar ratio of ZDA. This trend could be explained by the initiation and chain-transfer abilities for radical polymerization of the additives. Mixing these additives in a small amount to the solid monomers is a facile and efficient method to accelerate the solid-state polymerization.

Polymer Journal (2013) 45, 1007-1012; doi:10.1038/pj.2013.22; published online 6 March 2013

Keywords: diphenyl disulfide; divalent metal unsaturated carboxylate; peroxide; thermal solid-state polymerization; thiophenol

\section{INTRODUCTION}

Solid-state polymerization is an environment-friendly process because no organic solvent is required during the reaction. If topochemical conditions are achieved in the course of polymerization, stereoregular polymers can be prepared, for example, solid-state polymerization of diolefin, ${ }^{1}$ diacetylene ${ }^{2}$ and dienes. ${ }^{3,4}$ On the other hand, nontopochemical solid-state polymerization is also known. In our previous study, acrylate and acrylamide with long-alkyl substituents ${ }^{5,6}$ exhibiting non-topochemical solid-state polymerization were selected, and their polymerization behaviors in nanocrystals were compared with those of bulk crystals. ${ }^{7}$ In this connection, metal salts of acrylic acid are interesting because their melting points are higher than those of long-alkyl-substituted derivatives and thus various solid-state polymerization conditions can be examined over a wide temperature range. In the present study, zinc diacrylate (ZDA) was used as a monomer, and its thermal solid-state polymerization was investigated. ZDA is currently used as an additive for polymers to improve their thermal and mechanical properties. ${ }^{8,9}$ Although solidstate reactions of some metal $\alpha, \beta$-unsaturated carboxylates, such as alkali acrylates, ${ }^{10}$ sodium but-2-enoate ${ }^{11}$ and calcium di(but-2enoate), ${ }^{12}$ have been reported, their polymerization was initiated by $\gamma$-ray irradiation. The polymer from solvated lithium acrylate obtained by thermal treatment has only been reported as amorphous. ${ }^{13}$ Polymerization of ZDA in the solution state ${ }^{14,15}$ and the thermal behavior of $\mathrm{ZDA}^{16}$ have also been reported. However, a detailed study on the thermal solid-state polymerization behavior of ZDA has not been performed.

Solid-state chain polymerization was generally stimulated by highenergy electromagnetic waves, such as ultraviolet and $\gamma$-ray radiation, or by thermal annealing. However, each of these methods has disadvantages. For example, ultraviolet irradiation may also stimulate undesired photoreactions other than polymerization. $\gamma$-ray irradiation requires facilities that are designed for radiation safety, which are not common. Although thermal annealing is a simple treatment, some compounds do not exhibit high thermal polymerizability below their melting points, irrespective of the degree of photopolymerizability. Thus, a more universal stimulus for solid-state polymerization is worth investigating. We have been studying initiator-induced solidstate polymerization, in which reagents attacking from the crystal surfaces initiate the polymerization reactions of the crystals. We found that water-soluble radical initiators could start topochemical polymerization of diacetylene crystals in water. ${ }^{17-19}$ Similarly, the addition of radical initiators to ZDA is expected to promote thermal polymerization. In this study, the effects of additives, such as diphenyl

${ }^{1}$ Department of Organic Device Engineering, Graduate School of Science and Engineering, Yamagata University, Yonezawa, Japan and ${ }^{2}$ Research \& Development HQ, Sumitomo Rubber Industries, Kobe, Japan

Correspondence: Professor S Okada, Department of Organic Device Engineering, Graduate School of Science and Engineering, Yamagata University, 4-3-16 Jonan, Yonezawa, Yamagata 992 8510, Japan.

E-mail: okadas@yz.yamagata-u.ac.jp

Received 1 October 2012; revised 19 December 2012; accepted 27 December 2012; published online 6 March 2013 
disulfide (DPDS) and thiophenol (TP) derivatives and dicumyl peroxide (DCP), were also investigated.

\section{EXPERIMENTAL PROCEDURE}

Selected additives for ZDA solid-state polymerization were DPDS and bis(4chlorophenyl) disulfide (BCPDS) as disulfide derivatives, 4-chlorothiophenol (CTP) as a TP derivative, and DCP as a peroxide. ZDA and DCP were purchased from Sigma-Aldrich Co. (St Louis, MO, USA). DPDS was purchased from Wako Pure Chemical Industries, Ltd. (Osaka, Japan). BCPDS and CTP were purchased from Tokyo Chemical Industry Co., Ltd. (Tokyo, Japan). All chemicals were used as received.

All samples were well ground using a mortar and a pestle, and the ground powders were sealed in Pyrex tubes with evacuation. The sealed samples were soaked in a temperature-controlled oil bath. After heating for a set number of hours, the samples were cooled to room temperature, and the resulting solids were taken out from the tubes. The conversion to the polymer was obtained as follows. In all cases, the reacted powder was first weighed. Next, ZDA was washed out with methanol. For the samples including additives, chloroform was also used to rinse off the additives. The remaining portion was dried, and the conversion was obtained from the mass ratio of the remaining portion to the original whole powder. As the thermal solid-state reaction of ZDA did not occur homogeneously, especially in the case of additive mixing or at low temperature, the variation of the obtained conversion values was relatively large. Thus, the conversions were determined as the average values of two or more experiments. As reference experiments, bulk polymerization of dodecyl acrylate with and without additives was performed in the sealed Pyrex tubes following the solid-state polymerization experiments with ZDA.

Differential scanning calorimetry (DSC) and thermogravimetry (TG)/ differential thermal analysis were performed using Seiko Instruments (Chiba, Japan) DSC 220 and TG/differential thermal analysis 220 apparatuses with a heating rate of $10^{\circ} \mathrm{C}$ per min under a nitrogen atmosphere. Infrared spectra were recorded on a Horiba FT-210 spectrometer (Horiba, Kyoto, Japan). Solidstate ${ }^{13} \mathrm{C}$ NMR spectra were obtained with pulse sequences for cross polarization/magic-angle spinning (CP/MAS) and total suppression of spinning sidebands using a JEOL ECX-400 spectrometer (JEOL, Akishima, Japan). The methylene carbon of adamantane at 29.5 p.p.m. was used as an external standard. X-ray diffraction patterns were measured using a Rigaku RAD-rA diffractometer (Rigaku, Akishima, Japan) with a $\mathrm{Cu} K_{\alpha}$ source. Elemental analysis was performed using a PerkinElmer 2400II analyzer (PerkinElmer, Waltham, MA, USA) at the Elementary Analysis Laboratory, Department of Polymer Science and Engineering, Yamagata University.

\section{RESULTS AND DISCUSSION}

Figures 1a and $\mathrm{b}$ show the DSC and TG/differential thermal analysis curves of ZDA, respectively. ZDA maintained its solid state through the temperature-elevating process. In the DSC curve, an endothermic peak exists at $\sim 130{ }^{\circ} \mathrm{C}$. In the TG curve, the weight loss was initiated at $\sim 130{ }^{\circ} \mathrm{C}$. The thermal behaviors of ZDA, ${ }^{16}$ its polymer (PZDA) prepared by solution polymerization ${ }^{16}$ and PZDA synthesized from polyacrylate and zinc carbonate ${ }^{20}$ have been reported, and the weight loss observed for temperatures below $300{ }^{\circ} \mathrm{C}$ was generally attributed to the removal of solvent molecules. However, in the present case, the peak is not for evaporation of the included solvent because the measured analytical value of the original ZDA coincided with the calculated value for $\mathrm{C}_{6} \mathrm{H}_{6} \mathrm{O}_{4} \mathrm{Zn}$, that is, found: $\mathrm{C}, 34.98 ; \mathrm{H}, 2.57 \%$. calculated: C, 34.73; H, 2.91\%. Thus, partial elimination of ZDA was indicated at temperatures greater than $130{ }^{\circ} \mathrm{C}$. Exothermic peaks were observed above $\sim 170{ }^{\circ} \mathrm{C}$ from both DSC and TG/differential thermal analysis, as shown in Figure 1. These peaks are due to solid-state polymerization, which was first confirmed by insolubility in the monomer-soluble solvent. The thermal conversion of ZDA to PZDA was investigated by the gravimetric method. Greater than $90 \%$ conversion was obtained after $15 \mathrm{~min}$ at $250{ }^{\circ} \mathrm{C}$ and after $30 \mathrm{~min}$ at $220^{\circ} \mathrm{C}$. The conversion changes of $\mathrm{ZDA}$ at 200 and $170^{\circ} \mathrm{C}$ are displayed in Figures 2a and b, respectively. The error bars associated with the dots indicate the s.d. values for the data at the same heating time. At $200{ }^{\circ} \mathrm{C}$, the conversion increases monotonically and quantitative conversion was achieved after $\sim 8 \mathrm{~h}$. On the other hand, at $170{ }^{\circ} \mathrm{C}$, the conversion was saturated at $\sim 40 \%$. As $170{ }^{\circ} \mathrm{C}$ is near the lower-limit temperature of the thermal polymerization and thermal conduction in the solid state is considered not to be uniform, the conversion varied in a relatively wide manner. From these results, $170^{\circ} \mathrm{C}$ is insufficient for thermal solid-state polymerization of ZDA. $\mathrm{X}$-ray powder diffraction experiments were performed for ZDA before and after heating (Figure 3). The crystalline feature disappeared after heating, indicating that this polymerization progressed in a non-topochemical manner.

Next, we added DPDS or BCPDS to ZDA with a molar ratio of $1 / 60$. The conversion curves for the DPDS and BCPDS cases are shown in Figures $4 \mathrm{a}$ and $\mathrm{b}$, respectively. In both cases, the conversions improved to $>60 \%$ after heating at $170{ }^{\circ} \mathrm{C}$ for $10 \mathrm{~h}$, suggesting that the reaction rate increased compared with the case of ZDA alone. The polymer structures were investigated by ${ }^{13} \mathrm{C}$ NMR spectroscopy (Figure 5). ZDA exhibited peaks at 129 and 133 p.p.m. due to the olefinic carbons and a peak at 175 p.p.m. due to the carboxylate carbon in $\mathrm{CD}_{3} \mathrm{OD}$, as shown in Figure 5a. In the solid state, the peaks for the olefinic and carboxylate carbons appeared in the region of 129-135 p.p.m. and 174-178 p.p.m., respectively (Figure 5b). After thermal annealing at $200{ }^{\circ} \mathrm{C}$ for $20 \mathrm{~h}$, the conversion became quantitative (see Figure 2a) and the spectrum shown in Figure $5 \mathrm{c}$ was attained. New broad peaks appeared between 30 and 50 p.p.m., which corresponded to the $s p^{3}$ carbons of the methylene chains in the polymer backbones produced. Another new peak at $\sim 185$ p.p.m. could be assigned to the carboxylate carbons attached to the saturated polymer backbones. From these results, the polymerization scheme is the addition polymerization of ZDA. However, the peaks at $\sim 132$ and 175 p.p.m., which were also observed in the monomer spectrum, still remained. Thus, the main structure of PZDA can be described as that shown in Figure 6. This was also confirmed by the infrared spectra (Figure 7). The $\mathrm{C}=\mathrm{C}$ stretching vibration of $\mathrm{ZDA}$ at $\sim 1650 \mathrm{~cm}^{-1}$ decreased after heating to $200^{\circ} \mathrm{C}$. However, this peak remained as a shoulder, as indicated by an arrow in Figure $7 \mathrm{~b}$. The
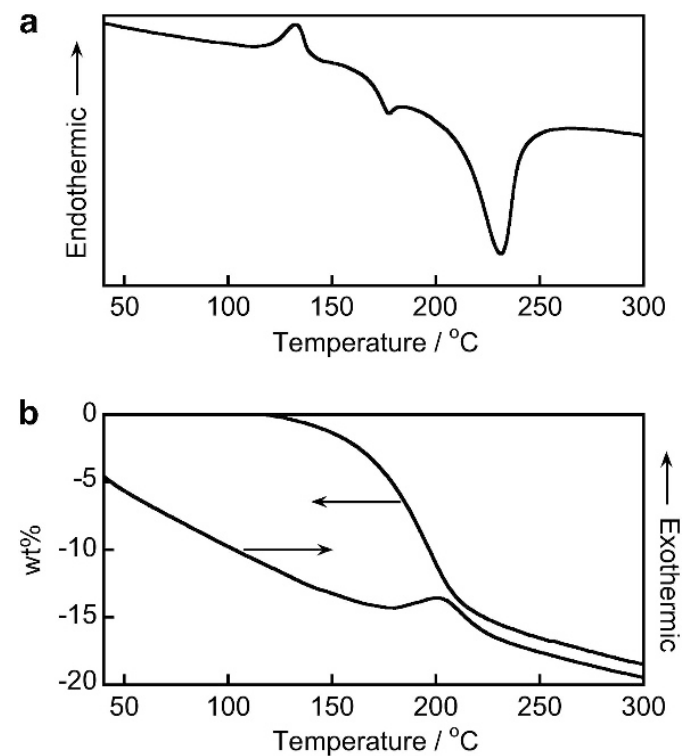

Figure 1 (a) DSC and (b) TG/differential thermal analysis curves of ZDA. 

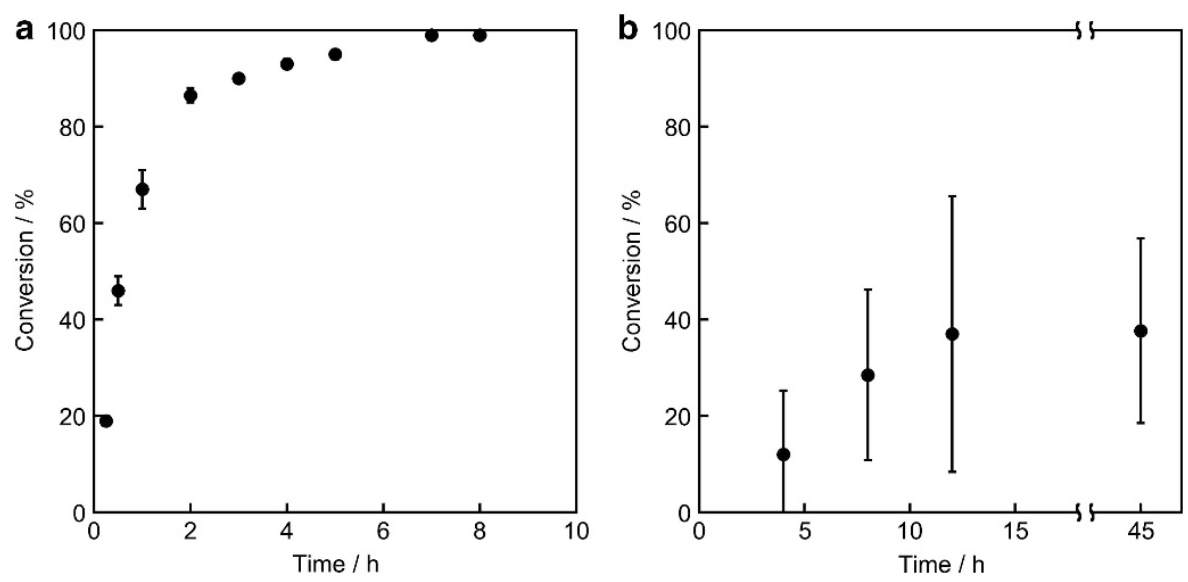

Figure 2 The conversion of ZDA at (a) $200^{\circ} \mathrm{C}$ and (b) $170^{\circ} \mathrm{C}$ depending on the annealing time.

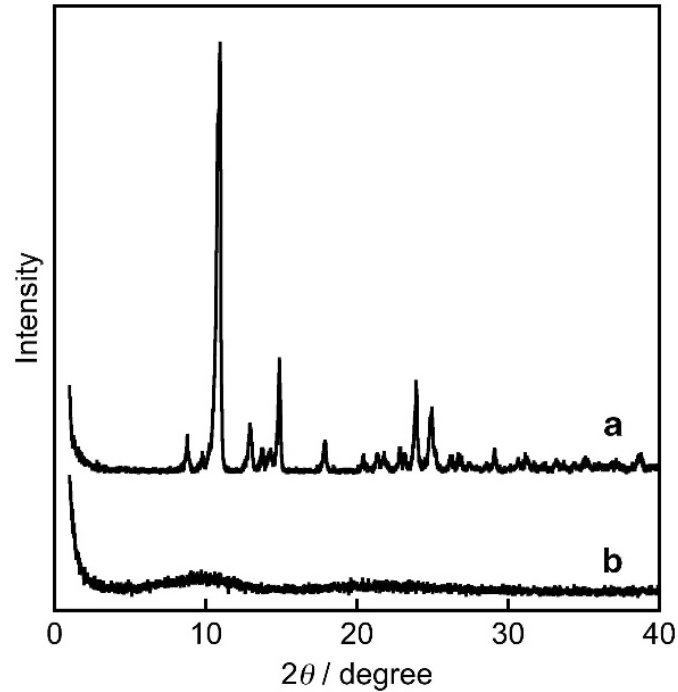

Figure 3 X-ray powder diffraction patterns of (a) ZDA and (b) PZDA obtained after heating at $200^{\circ} \mathrm{C}$ for $20 \mathrm{~h}$.

broadening of the peaks related to carboxylate appearing from 1400$1600 \mathrm{~cm}^{-1}$ indicates the PZDA structure is inhomogeneous due to non-topochemical polymerization. The acceleration of ZDA polymerization by DPDS was also confirmed by the ${ }^{13} \mathrm{C}$ NMR spectrum (Figure 5d). The unpolymerized acrylate portion significantly decreased at $200^{\circ} \mathrm{C}$, even with a shorter annealing time. When ZDA with DPDS was annealed at $170^{\circ} \mathrm{C}$ for $20 \mathrm{~h}$, a similar spectrum to Figure $5 \mathrm{c}$ was obtained. As the thermal mass reduction of ZDA was confirmed to be $<5 \%$ at $170{ }^{\circ} \mathrm{C}$ and $<11 \%$ at $200{ }^{\circ} \mathrm{C}$ for all cases using TG, only a small fraction of the sample is due to unidentified structures. We propose that the major polymer structure is that shown in Figure 6.

When CTP was added to ZDA with a molar ratio of $1 / 60$, only a slight increase of the conversion rate was observed compared with the case of ZDA (Figure 4c). However, when the molar ratio of CTP to ZDA was increased to $1 / 30$, the final conversion rate was improved to $\sim 90 \%$. When DCP was added to ZDA with a molar ratio of $1 / 60$, the reaction rate significantly accelerated. For a 20 -min anneal at $170{ }^{\circ} \mathrm{C}$, greater than $90 \%$ conversion was obtained, and similar results were even achieved for annealing within $1 \mathrm{~h}$ at $140^{\circ} \mathrm{C}$. Figure $4 \mathrm{~d}$ shows the conversion changes of a ZDA-DCP $(60: 1)$ mixture at $110^{\circ} \mathrm{C}$. Under this heating condition, it took $10 \mathrm{~h}$ to obtain $>90 \%$ conversion. Further addition to the ZDA-DCP system was also performed. Figures $4 \mathrm{e}$ and $\mathrm{f}$ show the conversion changes at $110^{\circ} \mathrm{C}$ of the ZDA-BCPDSDCP (60:1:1) and ZDA-CTP-DCP (60:1:1) mixtures, respectively. Although the final conversion became almost quantitative, the initial reaction rate of the ternary systems seemed to be slower than that of the ZDA-DCP binary system.

From these results, the qualitative order of the reaction rates of ZDA is as follows: ZDA $<$ ZDA-DPDS, ZDA-TP $<<$ ZDA-DPDSDCP, ZDA-TP-DCP $<$ ZDA-DCP. Generally, spontaneous thermal polymerization of a vinyl monomer alone is considered to progress via a radical mechanism. In addition, DCP is well known as a radical initiator, and the ZDA polymerization rate was largely enhanced by DCP addition. DPDS is also known to generate PhS $\bullet .^{21}$ Based on these points, the mechanism of this series of polymerization reactions should be based on the radical process. If we consider the role of additives as radical initiators, the bond dissociation energy (BDE), which is necessary to cleave a bond in the homolytic manner $(\mathrm{X}-\mathrm{X} \rightarrow$ $\mathrm{X} \bullet+\bullet \mathrm{X})$, is a good index for comparison. Table 1 summarizes reported BDEs of the related compounds in this study. ${ }^{22-26}$ Differences exist in the reported BDEs, even in the same compounds, and the BDE of BCPDP was not successfully located in the literature. Nevertheless, we could estimate the order of the BDEs among DCP, DPDS and CTP from Table 1, including the value for non-substituted TP. The order of BDE is DCP $<$ DPDS $<$ CTP. From this order, the higher reactivity by DCP addition compared with that by DPDS addition can be qualitatively explained because the lower BDE indicates the higher ability of radical generation by homolytic cleavage.

On the other hand, the reaction rates of the DPDS derivatives were similar to those of CTP, irrespective of the higher BDE of CTP. This result suggests that the main role of the additives is different between the DPDS and TP derivatives. In fact, the DPDS and TP derivatives are known as chain-transfer agents rather than radical initiators. The chain transfer constants for methyl methacrylate ${ }^{27}$ of DPDS and BCPDS have been reported to be $8.50 \times 10^{-3}$ and $1.17 \times 10^{-2}$ at $60{ }^{\circ} \mathrm{C}$, respectively, ${ }^{28}$ while those of TP at 45 and $60^{\circ} \mathrm{C}$ were $4.7^{29}$ and $2.7,^{30}$ respectively. The constant of CTP at $45^{\circ} \mathrm{C}$ has also been reported to be $4.6 .{ }^{29}$ Thus, the chain-transfer constants of the TP derivatives are over two orders of magnitude larger than those of the DPDS derivatives, implying that the contribution of the TP derivatives as chain-transfer agents, even in the polymerization reaction of $\mathrm{ZDA}$, is much larger than that of the DPDS derivatives. 

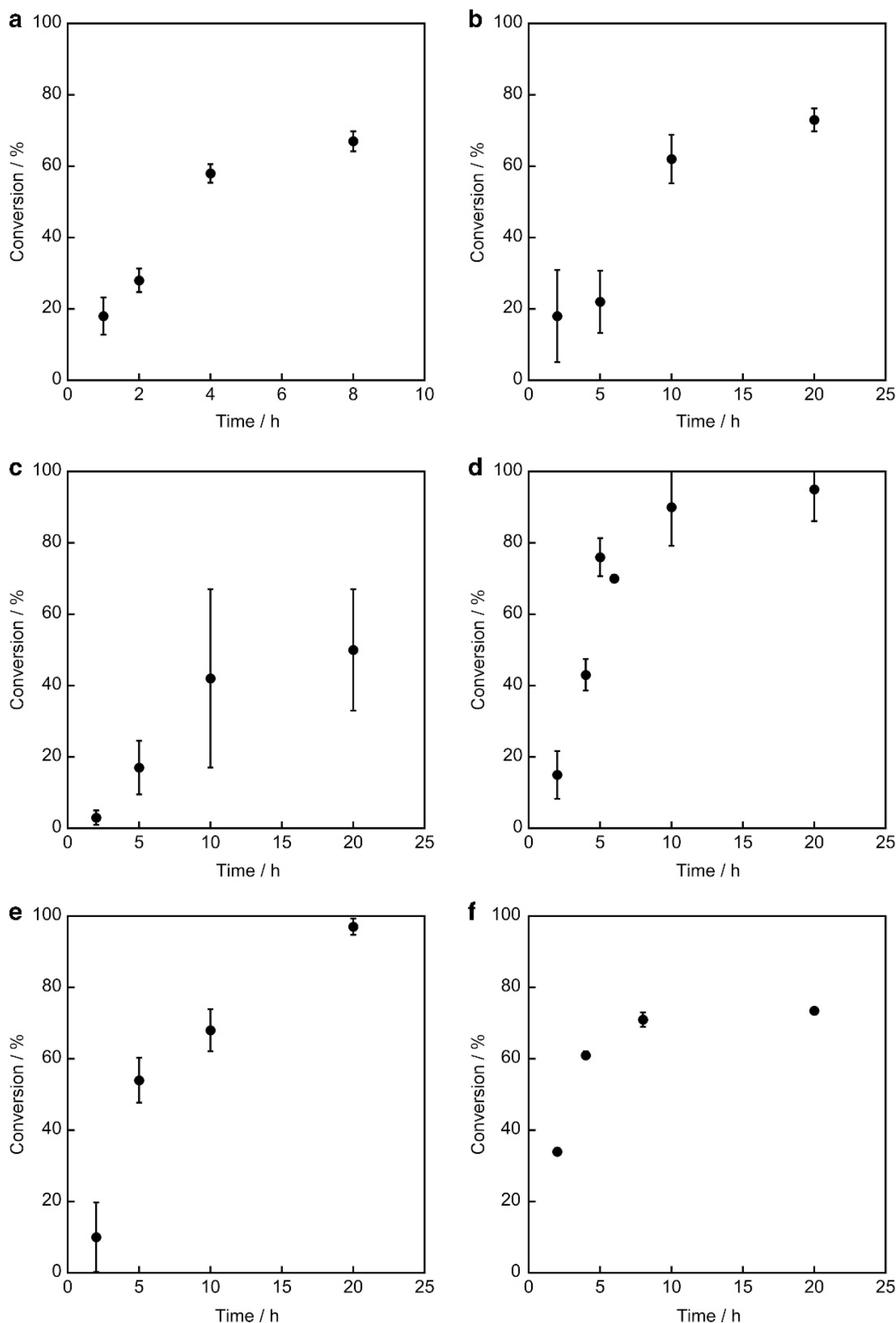

Figure 4 The dependence of the conversion of ZDA on the heating time: (a) ZDA with DPDS $(60: 1)$ at $170{ }^{\circ} \mathrm{C}$, (b) ZDA with BCPDS (60:1) at $170{ }^{\circ} \mathrm{C}$, (c) ZDA with CTP $(60: 1)$ at $170^{\circ} \mathrm{C}$, (d) ZDA with DCP $(60: 1)$ at $110^{\circ} \mathrm{C}$, (e) ZDA with BCPDS and DCP $(60: 1: 1)$ at $110^{\circ} \mathrm{C}$ and (f) ZDA with CTP and DCP $(60: 1: 1)$ at $110^{\circ} \mathrm{C}$.

Plausible reaction schemes of the additives as initiators and chaintransfer agents are shown in Figure 8. When the additive acts as an

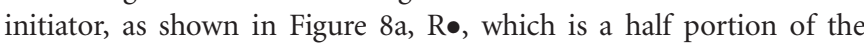
initiator molecule, first attacks the crystal surface to start the propagation reaction. In the crystal, only monomer molecules exist, and the reaction continues within the crystals until the radical end is quenched. In the ideal topochemical polymerization, the termination reaction can occur on the other end of the crystal surface by radical coupling between the polymer end and the outside R•. In this reaction scheme, one additive molecule is consumed during one polymer chain production. Thus, to increase the conversion, additive molecules should be continuously cleaved throughout the reaction period. On the contrary, when the reaction is not topochemical, chain-transfer reaction through monomers within the crystals is possible. The direction of the propagation reaction may change, and the combination or disproportionation between two polymer 


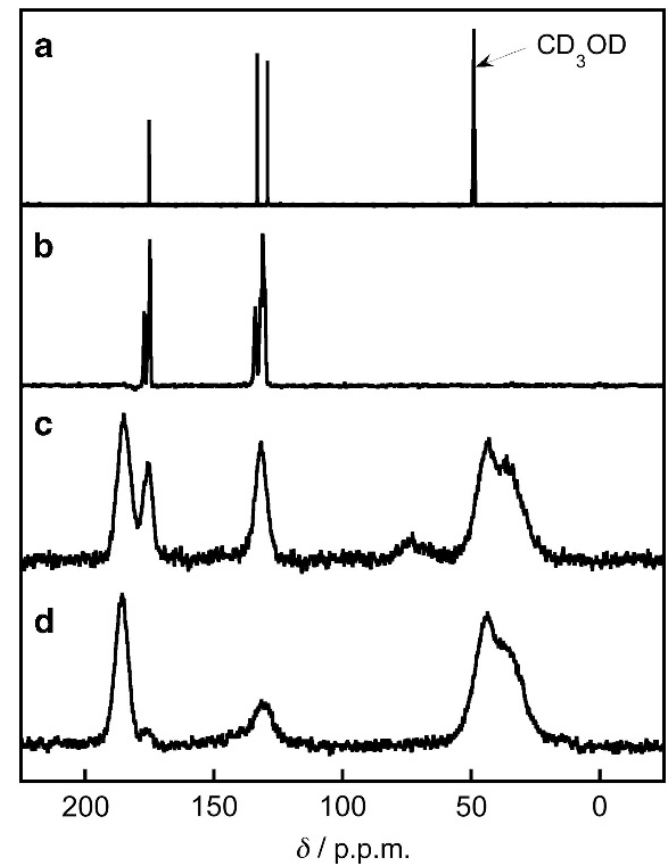

Figure $5{ }^{13} \mathrm{C}$ NMR of ZDA before and after thermal annealing: (a) and (b) ZDA, (c) ZDA after annealing at $200{ }^{\circ} \mathrm{C}$ for $20 \mathrm{~h}$, and (d) ZDA with DPDS after annealing at $200^{\circ} \mathrm{C}$ for $1 \mathrm{~h}$. Spectrum (a) was obtained in $\mathrm{CD}_{3} \mathrm{OD}$ solution, while spectra (b), (c) and (d) were measured in the solid state. Peak intensities were normalized to the largest peak in each spectrum.

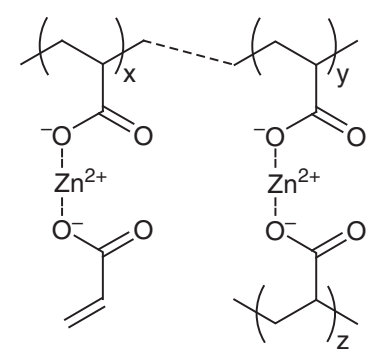

Figure 6 The proposed main structure of PZDA.

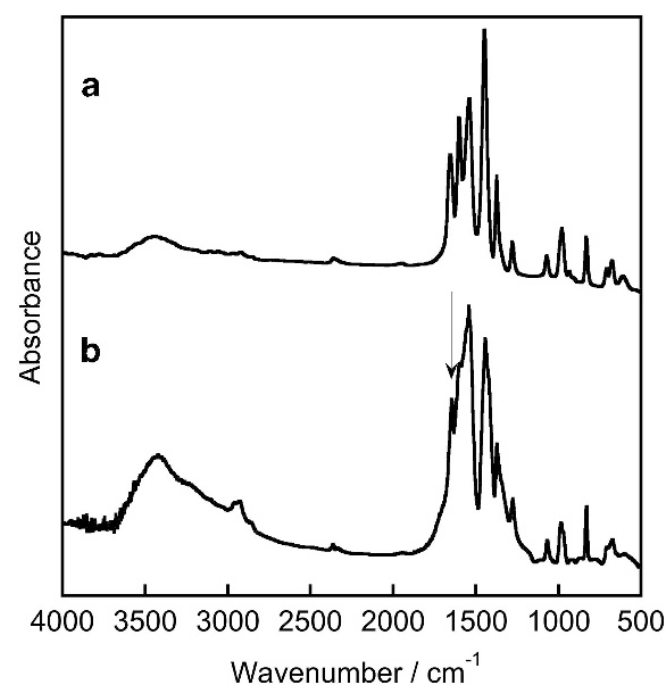

Figure 7 Infrared spectra of ZDA (a) before and (b) after heating at $200^{\circ} \mathrm{C}$. An arrow in $\mathbf{b}$ indicates the remaining stretching vibration band of $\mathrm{C}=\mathrm{C}$.
Table 1 Reported bond dissociation energy (BDE)

$\begin{array}{lll}\text { Dissociation bond in compound } & & \\ \text { BDE/ } \mathrm{kJ} \mathrm{mol}^{-1} & & \\ \text { Reference }\end{array}$

a Dotted lines indicate dissociation bonds.

bThe recommended values in Luo et al. ${ }^{24}$

$$
\begin{aligned}
\mathrm{R}^{\prime} \mathrm{R}^{\prime} \underset{\mathrm{A}}{\longrightarrow} \mathrm{R} \cdot+\cdot \mathrm{R}^{\prime} \\
\text { DPDS: }-\mathrm{R}=-\mathrm{R}^{\prime}=-\mathrm{SAr} \\
\text { TP: }-\mathrm{R}=-\mathrm{SAr},-\mathrm{R}^{\prime}=-\mathrm{H} \\
\bigoplus_{X} \mathrm{ZDA}:-\mathrm{X}=-\mathrm{CO}_{2}^{-} \cdot \frac{1}{2} \mathrm{Zn}^{2+}
\end{aligned}
$$
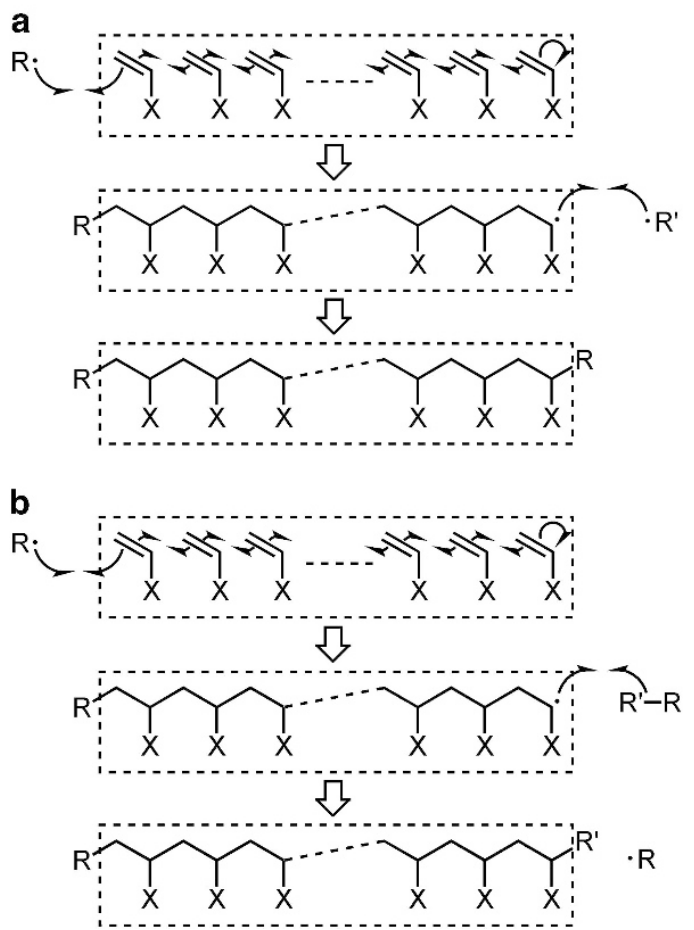

Figure 8 Plausible solid-state polymerization schemes of ZDA using DPDS and TP derivatives as additives. Schemes (a) and (b) are for the cases of additives acting as initiators and chain-transfer agents, respectively. The rectangles composed of dashed lines indicate crystals where only ZDA molecules are regularly aligned.

radical ends may also occur. In this case, the number of reacted monomers per initial radical species can increase compared with that of the ideal topochemical polymerization. When the additive acts as a 
chain-transfer agent, as shown in Figure 8b, radicals at the end of the polymer chains appearing on the crystal surfaces can be transferred to the additive residues, and they can start polymerization of other arrays of monomers in crystals after migration onto the crystal surfaces. This contribution also increases the solid-state polymerization rate.

As a reference experiment, bulk polymerization of dodecyl acrylate as a liquid monomer was performed in sealed tubes at $170{ }^{\circ} \mathrm{C}$ for $8 \mathrm{~h}$. Immediately after the thermal treatment, the samples with the DPDS derivatives, that is, the addition of DPDS or BCPDS in $1 / 60$ molar ratio, turned into gels. A viscosity increase relative to the pure monomer samples was observed for the samples with CTP in $1 / 60$ molar ratio. These results suggest that the DPDS derivatives largely contributed to polymerization as initiators and that there was some contribution of CTP as an initiator. In summary, the chaintransfer ability of DPDS is less than that of TP, although homolytic cleavage of DPDS is easier than that of TP. These two effects complemented each other, resulting in similar reaction rates for ZDA solid-state polymerization.

In the ternary system, that is, when DPDS or TP was added to a ZDA-DCP binary system, the reaction rate slightly decreased compared with the binary system. This slight decrease indicates that highly reactive $\mathrm{RO} \bullet$ from DCP was deactivated by DPDS or TP before reacting with $\mathrm{ZDA}$. The possible reaction schemes are summarized as the following equations.

$$
\begin{aligned}
& \mathrm{R}^{\prime \prime} \mathrm{O}-\mathrm{OR}^{\prime \prime} \rightarrow 2 \mathrm{R}^{\prime \prime} \mathrm{O} \bullet \\
& \mathrm{R}^{\prime \prime} \mathrm{O} \bullet+\mathrm{ArS}-\mathrm{SAr} \rightarrow \mathrm{R}^{\prime \prime} \mathrm{O}-\mathrm{SAr}+\mathrm{ArS} \bullet
\end{aligned}
$$

$$
\mathrm{R}^{\prime \prime} \mathrm{O} \bullet+\mathrm{ArS}-\mathrm{H} \rightarrow \mathrm{R}^{\prime \prime} \mathrm{O}-\mathrm{H}+\mathrm{ArS} \bullet
$$

Equations 2 and 3 are for the reaction with DPDS and TP derivatives, respectively. Although we could not find the BDE of $\mathrm{PhS}-\mathrm{OPh}$, the energy difference between the before and after reaction (2) is roughly estimated to be $\sim 20 \mathrm{~kJ} \mathrm{~mol}^{-1}$, based on the BDE values of $271 \mathrm{~kJ} \mathrm{~mol}^{-1}$ for HS-SH and $295 \mathrm{~kJ} \mathrm{~mol}^{-1}$ for HO-SH. ${ }^{24}$ On the other hand, the BDE of PhS-H is $\sim 350 \mathrm{~kJ} \mathrm{~mol}^{-1}$, as shown in Table 1. By using a BDE of $\sim 370 \mathrm{~kJ} \mathrm{~mol}^{-1}$ for $\mathrm{PhO}-\mathrm{H},{ }^{24}$ the energy difference between the before and after reactions (3) is also estimated to be $\sim 20 \mathrm{~kJ} \mathrm{~mol}^{-1}$. Thus, the reaction rates of (2) and (3) seem to be comparable, and the degrees of deactivation are similar.

\section{CONCLUSION}

Thermal solid-state polymerization of ZDA was investigated, along with the effect of additives on the polymerization. Spontaneous thermal polymerization of $\mathrm{ZDA}$ is non-topochemical, and it is initiated for temperatures of over $\sim 170^{\circ} \mathrm{C}$. The polymerization mainly occurs at one of the acrylate moieties of ZDA, although a part of the monomer structure is eliminated during the polymerization. By adding DPDS or TP, the polymerization rate increases due to the radical initiation and chain-transfer abilities of the additives. A significantly accelerated polymerization rate was obtained by adding DCP, which can polymerize ZDA even at $110^{\circ} \mathrm{C}$. The addition of a small amount of peroxide, disulfide or TP was found to be quite useful to promote solid-state polymerization at lower temperatures compared with the temperature at which spontaneous thermal polymerization begins.
1 Hasegawa, M. \& Suzuki, Y. Four-center type photopolymerization in the solid state: Poly-2,5-distrylpyrazine. J. Polym. Sci., B: Polym. Lett. 5, 813-815 (1967).

2 Wegner, G. Topochemische reaktionen von monomeren mit konjugierten dreifachbindungen I. Mitt.: polymerisation von derivaten des 2.4-hexadiin-1.6-diols im kristallinen zustan. Z. Naturforsch. 24b, 824-832 (1969).

3 Tieke, B. Chemical reactions in perovskite-type layer structures. Mol. Cryst. Liq. Cryst. 93, 119-145 (1983).

4 Matsumoto, A., Matsumura, T. \& Aoki, S. Stereospecific polymerisation of diethyl $(Z, Z)$ hexa-2,4-dienedioate in the crystalline state. J. Chem. Soc., Chem. Commun. 1389-1390 (1994).

5 Shibasaki, Y., Nakahara, H. \& Fukuda, K. Solid-State polymerization of long chain vinyl compounds. I. Effect of molecular arrangement on polymerizability of octadecyl methacrylate. J. Polym. Sci., Polym. Chem. Ed. 17, 2387-2400 (1979).

6 Shibasaki, Y. \& Fukuda, K. Surface effects on phase transition behaviour and thermal polymerisation of long-chain compounds in micro DSC measurements. Thermochim. Acta. 183, 199-208 (1991).

7 Abe, H., Okada, S., Kimura, T. Shimada, S., Matsuda, H. Masuhara, A., Kasai, H. \& Oikawa, H. Nanocrystal fabrication of acrylic acid derivatives with a long-alkyl group and their solid-state polymerization. Mol. Cryst. Liq. Cryst. 492, 70-76 (2008).

8 Costin, R., Ekwall, R. \& Nagel, W. Metallic coagents for curing elastomers with scorch safet. Kaut. Gummi. Kunstst. 45, 648-650 (1992).

9 Ahn, N. Effects of diacrylate monomers on the bond strength of polymer concrete to wet substrates. J. Appl. Polym. Sci. 90, 991-1000 (2003).

10 Morawetz, H. \& Rubin, I. D. Polymerization in the crystalline state. II. Alkali acrylates and methacrylates. J. Polym. Sci. 57, 669-686 (1962).

11 Diaz de Delgado, G. C., Wheeler, K. A., Snider, B. B. \& Foxman, B. M. Stereospecific $\gamma$-ray-induced trimerization of crystalline sodium trans-2-butenoate. Angew. Chem. Int. Ed. Engl. 30, 420-422 (1991).

12 Cho, T. H., Chaudhuri, B., Snider, B. B. \& Foxman, B. M. Stereospecific $\gamma$-ray-induced dimerization of crystalline bis(trans-but-2-enoate)calcium. J. Chem. Soc., Chem. Commun. 1337-1338 (1996)

13 Beck, H. P. \& Trübenbach, P. Untersuchungen an wasserfeiem lithiumacrylat, lithiumacrylat-tetartoshydrat und -hektonmethanolat. Chem. Ber. 125, 331-336 (1992)

14 Wojtczak, Z. \& Czerniawski, T. Polymerization of Zinc acrylate in dimethylformamide. Acta. Polym. 40, 409-411 (1989).

15 Sadeghi, S. M. -T. Synthesis, characterization and thermal stability study of polyelectrolytes (some transition metal salts). Iran. Polym. J. 14, 657-666 (2005).

16 Gronowski, A. \& Wojtczak, Z. The thermal decompositions of some transition metal acrylates and polyacrylates. J. Therm. Anal. 26, 233-244 (1983).

17 Arai, M. \& Okada, S. Polymerization of a butadiyne derivative in crystalline state stimulated by radical initiators. Chem. Lett. 35, 1012-1013 (2006).

18 Kato, S., Kinemuchi, T., Tatewaki, Y., Okada, S., Masuhara, A., Kasai, H. \& Oikawa, H. Radical-initiator-induced solid-state polymerization of butadiyne nanocrystals in water and their dispersion stabilization. J. Nanosci. Nanotechnol. 11, 3340-3344 (2011).

19 Kinemuchi, T., Moritani, Y., Tatewaki, Y. \& Okada, S. Fixation of surface-modified polydiacetylene nano/microcrystals on substrates. Jpn J. Appl. Phys. 50, 095202 (2011).

20 Allan, J. R., Bonner, J. G., Gerrard, D. L. \& Birnie, J. Structural characterization and thermal analysis studies of the compounds of manganese(II), cobalt(II), nickel(II), copper(II) and zinc(II) with poly(acrylic acid). Thermochim. Acta. 185, 295-302 (1991).

21 Miyashita, T., Matsuda, M. \& lino, M. Kinetics of the thermal decompositions of diaryl and dialkyl disulfides. Bull. Chem. Soc. Jpn 48, 3230-3235 (1975).

22 Zhou, W. \& Zhu, S. ESR study of peroxide-induced cross-linking of high density polyethylene. Macromolecules 31, 4335-4341 (1998).

23 Pedley, J. B., Naylor, R. D. \& Kirby, S. P. Thermochemical Data of Organic Compounds. 2nd edn (Chapman and Hal, London, New York, 1986).

24 Luo, Y. -R. Handbook of Bond Dissociation Energies in Organic Compounds (CRC, Boca Raton, 2003).

25 Borges dos Santos, R. M., Muralha, V. S. F., Correia, C. F., Guedes, R. C., Costa Cabral B. J. \& Martinho Simões, J. A. S-H bond dissociation enthalpies in thiophenols: a timeresolved photoacoustic calorimetry and quantum chemistry study. J. Phys. Chem. A 106, 9883-9889 (2002).

26 Bordwell, F. G., Zhang, X. -M., Satish, A. V. \& Cheng, J. -P. Assessment of the importance of changes in ground-state energies on the bond dissociation enthalpies of the $\mathrm{O}-\mathrm{H}$ bonds in phenols and the $\mathrm{S}-\mathrm{H}$ bonds in thiophenols. J. Am. Chem. Soc. 116, 6605-6610 (1994)

27 Berger, K. C. \& Brandrup, G. in Polymer Handbook. Brandrup, J. \& Immergut, E. H. (eds) 3rd edn, II/81-II/151 (John Wiley \& Sons, New York, Chichester, Brisbane, Toronto, Singapore, 1989).

28 Otsu, T., Kinoshita, Y. \& Imoto, M. The chain transfer mechanism of substituted diphenyl disulfides. Makromol. Chem. 73, 225-230 (1964).

29 Barton, S. C., Bird, R. A. \& Russell, K. E. The effect of phenols and aromatic thiols on the polymerization of methyl methacrylate. Can. J. Chem. 41, 2737-2742 (1963).

30 O'Brien, J. L. \& Gornick, F. Chain transfer in the polymerization of methyl methacrylate. I. Transfer with monomer and thiols. The mechanism of the termination reaction at 60'. J. Am. Chem. Soc. 77, 4757-4763 (1955) 